\title{
LETTER TO THE EDITOR \\ Factors associated with the development of pressure ulcers after spinal cord injury
}

\author{
Spinal Cord (2013) 51, 84; doi:10.1038/sc.2012.118; published online 25 September 2012
}

We have read 'Factors associated with the development of pressure ulcers (PUs) after spinal cord' by Eslami et al. ${ }^{1}$ with interest. Research on spinal cord injuries (SCIs) in EMRO (WHO Eastern Mediterranean Region) countries ${ }^{2}$ is sparse. On the basis of our experience of working with SCI population in Pakistan, we would like to offer the following comments:

- SCI management and rehabilitation in most of the developing countries of the world is inadequate. There are concerns about the pre-hospital immobilization and evacuation, ${ }^{3,4}$ lack of advanced imaging studies, ${ }^{5}$ inadequate access to early surgical care, very high cost of spinal surgical interventions ${ }^{6}$ and lack of SCI rehabilitation. ${ }^{3}$

- The lack of systematic data collection on SCI in developing countries is a major barrier toward calculating actual burden of disability of SCI and formulating long-term preventive strategies. ${ }^{5}$ Therefore, current study representing a large cohort representative of all regions of the country is invaluable.

- We face similar challenges in prevention of PU is SCI as there are no trained rehabilitation or skin care nurse available in Pakistan. PU risk assessment is not routinely carried out or documented in high-risk cases such as SCI. There is no provision of community health care nurses or home visits for the SCI patients. The attitude of our health care professionals toward PUs recognition and prevention has been described as casual. ${ }^{3}$ This results in a high prevalence of PU in SCI. The reported incidence of PU in SCI in Pakistan is $28-39 \% .^{3,7}$

- We have identified four major reasons for PU occurrence in our SCI population, that is, lack of knowledge regarding PU prevention on part of the doctors, inadequate change of posture, nonavailability of pressure-relief mattresses in the acute phase of management and delay in identification of early signs of skin breakdown. ${ }^{3,7}$ We wonder how many of these factors were present in this study?

- Our experience with pediatric SCI population also shows a reduced incidence of PU. The probable reasons might be presence of more adipose tissue, easy nursing care of kids and a skin more resilient to break down as compared with skin of an older patient.

- Lack of an intimate partner has been identified as a risk factor for development of PU by Eslami et al. Most of the developing countries in Asia have a combined family system with a trend to get married at an early age. In our experience being married is an advantage to SCI patient as the spouse (especially wives) acts as a lifelong care giver and can be a valuable resource in preventing PU. ${ }^{3}$

- PU prevention is a lifelong commitment by the patient to adhere to the instructions of pressure relief and skin care. In our experience this is very difficult to achieve in patients with low educational status, as pointed out by the authors. These patients are very difficult to counsel and are unable to benefit from the patient education material because of their inability to read.

- A quadriplegic in a developing country leads a very restricted life in most of the cases. Majority of them are confined to their homes and spend most of the time in their beds or wheel chairs, with no regular pressure relief (because of various reasons: lack of attendant, lack of knowledge about PU prevention, and so on). This contributes toward high incidence of PU in this vulnerable population.

- There is a need to conduct more extensive studies on epidemiology and complication profile of SCI in the EMRO region. We volunteer to lead a collaborative research project on Epidemiology of SCI in the EMRO region. Any suggestions and questions would be welcome.

\section{CONFLICT OF INTEREST}

The authors declare no conflict of interest.

Farooq A Rathore ${ }^{1}$ and Sahibzada Nasir Mansoor ${ }^{2}$ ${ }^{1}$ Department of Rehabilitation Medicine, Combined Military Hospital, Lahore Cantt, Pakistan and ${ }^{2}$ Department of Rehabilitation Medicine, Combined Military Hospital, Kohat Cantt, Pakistan E-mail: farooqrathore@gmail.com

1 Eslami V, Saadat S, Habibi Arejan R, Vaccaro AR, Ghodsi SM, Rahimi-Movaghar V. Factors associated with the development of pressure ulcers after spinal cord injury. Spinal Cord 2012; 50: 899-903.

2 World Health Organization. Countries in the WHO Eastern Mediterranean Region. Available from http://www.who.int/about/regions/emro/en/index.html. (Accessed 26 July 2012).

3 Rathore MF, Hanif S, Farooq F, Ahmad N, Mansoor SN. Traumatic spinal cord injuries at a tertiary care rehabilitation institute in Pakistan. J Pak Med Assoc 2008; 58: 53-57.

4 Rathore FA, Ayub A, Farooq S, New PW. Suicide bombing as an unusual cause of spinal cord injury: a case series from Pakistan. Spinal Cord 2011; 49: 851-854.

5 Rathore F. Spinal Cord Injuries in the Developing World. In: Stone JH and Blouin M (eds). International Encyclopedia of Rehabilitation. 2010. Available from http:// cirrie.buffalo.edu/encyclopedia/article.php?id=141\&language=en. (Accessed 26 July 2012).

6 Shamim MS, Ali SF, Enam SA. Non-operative management is superior to surgical stabilization in spine injury patients with complete neurological deficits: a perspective study from a developing world country, Pakistan. Surg Neurol Int 2011; 2: 166.

7 Rathore MFA, Rashid P, Butt AW, Malik AA, Gill ZA, Haig AJ. Epidemiology of spinal cord injuries in the 2005 Pakistan earthquake. Spinal Cord 2007; 45: 658-663. 